\title{
Waiting and Hope: Optimal Time Interval for Surgery After Long-Course Neoadjuvant Chemoradiotherapy in Patients With Locally Advanced Rectal Cancer
}

\author{
Chang Hyun Kim \\ Department of Surgery, Chonnam National University Hwasun Hospital, Chonnam National University Medical School, Gwangju, Korea
}

See Article on Page 241-247

Colorectal cancer is the most often diagnosed malignancy worldwide and is the second most common cancer in South Korea [1]. The treatment of locally advanced rectal cancer has changed continuously. Recently, preoperative chemoradiotherapy (CRT) has been the mainstay of treatment for this disease as it confers a high rate of local control and sphincter preservation [2]. Parameters for tumor sterilization related with radiotherapy are the total radiation dose, the dose per each fraction, and the time interval from the completion of radiotherapy to pathologic assessment of the tumor [3]. Many plausible methods, such as radiation dosage, type of concurrent chemotherapy, and various modalities of radiotherapy, have been tested. Meanwhile, the time interval from the day of completion of CRT to surgery has been recognized as a modifiable factor that may alter oncologic outcome [4]. Pathologic complete response (pCR) is now regarded as an independent predictor of long-term outcomes following preoperative CRT in patients with locally advanced rectal cancer. In terms of radiobiology, the radiation is given in small doses (1.8-2.0 Gy) for 5 to 7 weeks. The reason for this fractionated schedule is to permit the recovery of normal tissues from sublethal radiation damage. However, repopulation of tumor cells also occurs [5]. In a rectal adenocarcinoma, significant repopulation of tumor cells occurs 4 weeks after the completion of long-course radiotherapy [6], but this phenomenon can be delayed by combining chemo-

Correspondence to: Chang Hyun Kim, M.D.

Department of Surgery, Chonnam National University Hwasun Hospital, Chonnam National University Medical School, 322 Seoyang-ro, Hwasun 58128, Korea

Tel: +82-61-379-7646, Fax: +82-61-379-7661

E-mail: cksantiago8@gmail.com

ORCID code: https://orcid.org/0000-0002-1954-189X

(C) 2018 The Korean Society of Coloproctology

This is an open-access article distributed under the terms of the Creative Commons Attribution NonCommercial License (http://creativecommons.org/licenses/by-nc/4.0) which permits unrestricted noncommercial use, distribution, and reproduction in any medium, provided the original work is properly cited. therapeutic agents [7].

Although a consensus about when to perform surgery after preoperative CRT is still lacking, a minimum of 6 to 8 weeks after completion of preoperative CRT is recommended to achieve maximal tumor shrinkage. Several retrospective studies reported that increasing the delay after preoperative CRT is associated with greater tumor regression. However, the actual impact of delaying surgery is unknown. All of these studies have unavoidable biases. For example, the selection of surgical timing was determined by the surgeons and was influenced by the tumor response to preoperative CRT. The Lyon trial (short-course CRT) [4] and the GRECCAR-6 trial (long-course CRT) [8] were the only 2 prospective randomized studies on this issue. Especially, in the GRECCAR-6 trial, waiting 11 weeks after completion of preoperative CRT did not show any higher achievement of pCR after surgery, and the speculation is that new tumor sterilization after 6 to 8 weeks cannot be anticipated; instead, tumor re-growth by repopulation will be accelerated [8].

In this regard, Kim et al. [9] reported the effect of this time interval on the pathologic response for patients with rectal cancer. For the first time on this issue, they analyzed data selected from data provided by Health Insurance Review and Assessment (HIRA) Service. Unfortunately, the study had various limitations in terms of both the small number of patients, despite the data being drawn from a national database, and the short follow-up time. As recognized by Kim et al. [9], their study did not extract all the patient data-100 patients from each institution and the dates of radiotherapy and surgery were not available in the HIRA database in the middle of the study period; therefore, a clear conclusion could not be reached. Nevertheless, the author showed that delaying surgery until 9 to 11 weeks after long-course preoperative CRT increases tumor downstaging while delaying it by more than 11 weeks does not provide additional tumor regression. These results are consistent with those of the GRECCAR- 6 trial and the above-mentioned radiobiology [8].

In the future of healthcare, the use of big data will be inevitable, and the healthcare sector will be one of the sectors expected to 
benefit the most from big data. In Korea, the HIRA database has been widely used in many clinical studies. Along with this, the Korean Society of Coloproctology has recently been working on building a national database for colorectal cancer. In the future, we hope to see the results of representative research that uses these databases to overcome the above-mentioned limitations.

\section{CONFLICTS OF INTEREST}

No conflicts of interest are reported.

\section{REFERENCES}

1. Jung KW, Won YJ, Kong HJ, Lee ES; Community of PopulationBased Regional Cancer Registries. Cancer statistics in Korea: incidence, mortality, survival, and prevalence in 2015. Cancer Res Treat 2018;50:303-16.

2. Sauer R, Becker H, Hohenberger W, Rödel C, Wittekind C, Fietkau $\mathrm{R}$, et al. Preoperative versus postoperative chemoradiotherapy for rectal cancer. N Engl J Med 2004;351:1731-40.

3. Berger C, de Muret A, Garaud P, Chapet S, Bourlier P, ReynaudBougnoux A, et al. Preoperative radiotherapy (RT) for rectal cancer: predictive factors of tumor downstaging and residual tumor cell density (RTCD): prognostic implications. Int J Radiat Oncol Biol Phys 1997;37:619-27.
4. Francois Y, Nemoz CJ, Baulieux J, Vignal J, Grandjean JP, Partens$\mathrm{ky} \mathrm{C}$, et al. Influence of the interval between preoperative radiation therapy and surgery on downstaging and on the rate of sphincter-sparing surgery for rectal cancer: the Lyon R90-01 randomized trial. J Clin Oncol 1999;17:2396.

5. Kim JJ, Tannock IF. Repopulation of cancer cells during therapy: an important cause of treatment failure. Nat Rev Cancer 2005;5: 516-25.

6. Gasinska A, Richter P, Darasz Z, Niemiec J, Bucki K, Malecki K, et al. Gender-related differences in repopulation and early tumor response to preoperative radiotherapy in rectal cancer patients. J Gastrointest Surg 2011;15:1568-76.

7. Peters LJ, Withers HR. Applying radiobiological principles to combined modality treatment of head and neck cancer--the time factor. Int J Radiat Oncol Biol Phys 1997;39:831-6.

8. Lefevre JH, Mineur L, Kotti S, Rullier E, Rouanet P, de Chaisemartin C, et al. Effect of interval ( 7 or 11 weeks) between neoadjuvant radiochemotherapy and surgery on complete pathologic response in rectal cancer: a multicenter, randomized, controlled trial (GRECCAR-6). J Clin Oncol 2016;34:3773-80.

9. Kim MJ, Cho JS, Kim EM, Ko WA, Oh JH. Optimal time interval for surgery after neoadjuvant chemoradiotherapy in patients with locally advanced rectal cancer: analysis of Health Insurance Review and Assessment Service data. Ann Coloproctol 2018;34:2417. 